\title{
Employability and the UseMyAbility Online Tool: Raising Sports Students' Awareness to Inform the Development of Their Skills and Attributes
}

\author{
Nick Breeze ${ }^{1, *}$, Lerverne Barber ${ }^{1}$, Val Chapman ${ }^{2}$, Charlotte Beaman-Evans ${ }^{1} \&$ Kelvin Beeching ${ }^{1}$ \\ ${ }^{1}$ Institute of Sport and Exercise Science, University of Worcester, UK \\ ${ }^{2}$ Education Management Consultant, UK \\ *Correspondence: Institute of Sport and Exercise Science, University of Worcester, Henwick Grove, Worcester, \\ Worcestershire, UK. Tel: 44-1905-855-573. E-mail: n.breeze@worc.ac.uk
}

Received: February 11, 2016 Accepted: March 16, 2016 Online Published: April 17, 2016

doi:10.5430/jct.v5n1p62

URL: http://dx.doi.org/10.5430/jct.v5n1p62

\begin{abstract}
The collaborative project UseMyAbility (UMA) sought to reduce discrimination and enhance disabled graduates' employability through equipping them with the skills to match employability skills and attributes. An outcome from the project, completed in 2011, was a web-based tool which gave students advice on how to improve their employability. Subsequently, an online self-audit questionnaire was developed, which allowed students to record and map their employability skills and attributes. This paper reports on two projects that used this UMA online questionnaire with undergraduate sports students at a UK University. The first group were students undertaking a second-year Physical Education (PE) module and the second were students undertaking internships in a variety of sporting contexts. Drawing on data gained from questionnaires and student and mentor interviews, the two projects sought to evaluate the effectiveness of the UMA questionnaire for the students in these two contexts. It aimed to enhance students' employability profiles, enable them to benchmark and track their development, provide practical help in preparing job applications, tackle interview questions and develop evidence-based curricula vitae. It is hoped that through identifying ways of adapting the use of the questionnaire to these contexts, learning from participant data from the completion of the questionnaires, and gaining a better understanding of students' and mentors' perceptions of its use, that insights may be gained that will aid the wider adoption of the online tool.
\end{abstract}

Keywords: employability; self-audit; online questionnaire; physical education; internship

\section{Introduction}

\subsection{Background}

'Employability' is a term that has become widely used in higher education in the UK. It has been particularly in the ascendant during the last 15 years since publications such as the Dearing report (1997), with its recommendations of closer industry links and greater use of work experience, and the HEQC (1997) report, which stated that graduates should gain skills such as critical reasoning, analysis, synthesis, evaluation, and identifying and solving problems. In addition to official and academic reports, employers' organisations have also signalled that higher education should work with employers to incorporate employability skills into their curricula as well as forge closer links with outside organisations in order to provide work experience for students (Wright, Brinkley \& Clayton, 2010, p. 42).

Building on notions such as 'transferable skills' (Dearing, 1997, p. 59) and 'key skills' (Gillespie, 2001), employability can be viewed as an outcome from the 'new realities' following increasing governmental pressure for "higher education to contribute directly to national economic regeneration and growth" (Harvey, 2000, p. 4). However, Harvey (2001) also cautions that it is important not to confuse employability processes with outcomes, for example, getting a job. He questions the nature of an individual's employability, asking whether it indicates that a person will possess all the necessary attributes at the time of appointment, or whether it is developmental, meaning an individual would be able to demonstrate that they had the ability to quickly develop the necessary attributes for the post. 
Harvey (2001) noted that employability is perhaps best understood as a set of basic core- skills, or a larger set of generic attributes that could be specified by an employer. He calls this range of attributes 'dimensions', a concept that was later developed into 29 'competencies' (Kubler \& Forbes, 2005), for example, 'adaptability/flexibility', 'initiative', 'leadership' and 'teamwork/working with others'. Viewing these aspects from an employers' perspective, the Confederation of British Industry (CBI, 2009, p. 8) terms them 'attributes, skills and knowledge' and lists them as 'self-management', 'teamworking', 'business and customer awareness', 'problem solving', 'communication and literacy', 'application of numeracy' and 'application of information technology'. Underpinning all of these it notes, is a positive attitude and it also highlights 'entrepreneurship/enterprise' as an additional valued aspect of any potential employee. In a later study, concerning the development of a model for measuring employability, Dacre Pool and Sewell (2007, p.282) present their CareerEDGE Employability Development Profile (EDP), a model with five components ('career development learning', 'experience' (work and life), 'degree subject knowledge understanding and skills'; 'generic skills' and 'emotional intelligence'). Fifteen 'generic skills' are listed, alongside a consideration of 'enterprise and entrepreneurship skills'. The five-factor structure of the model was confirmed in a later study (Dacre Pool, Qualter \& Sewell, 2014). In the two projects described in this paper, these variously named aspects are termed 'skills' and 'attributes'.

When considering the most effective method of measuring employability, Harvey suggests that “... any evaluation of employability needs clearly to indicate areas for improvement and might be done by internal, longitudinal benchmarking that, over time, compares and evaluates outcomes..." (2001, p. 108). However, employability has been viewed as something somewhat more complex than this, as Yorke maintains:

Employability is [...] considerably more complex than some proponents of 'core', 'key' and 'transferable' skills have suggested, and is strongly aligned with the academic valuing of good learning (2006, p. 2).

Acknowledging that employability is both a curricular process and a set of achievements and potentials, he provides a working definition of employability as:

a set of achievements - skills, understandings and personal attributes - that makes graduates more likely to gain employment and be successful in their chosen occupations, which benefits themselves, the workforce, the community and the economy (p. 8).

As foreshadowed by two previously mentioned reports (Dearing, 1997; HEQC, 1997), collaboration between business and Universities has been acknowledged to have increased in recent years (Wilson, 2012, p. 1). There are many claimed benefits for student internships, including their use as a career management tool and to help them to "gain a better understanding of themselves and the ever more complex world of work" (Callanan \& Benzing, 2004, p. 88). Although these benefits are recognized, there have been various factors identified that need to be taken into account in order to make the most of the opportunities an internship can potentially provide (Stratta, 2004). However, internships have been identified as a valuable tool for providing students with workplace experience, and have been seen to add to key aspects of graduates' employability, especially in the current climate of pressures from the economy, increased competition and greater demands from employers (Helyer \& Lee, 2014).

From 2008, an opportunity for UK students to present to potential employers a formal record of their employability skills and attributes was provided through the Higher Education Achievement Report (Higher Education Academy, 2015). This record is aimed at enhancing students' employability through providing a clear record of their achievement at university in order to help employers gain a clear impression of their capabilities.

\subsection{Measuring Employability}

There have been various tools developed to map and audit students' skills development, each with their own foci. A tool developed at Queen's University Belfast (Tariq, Scott, Cochraine, Lee \& Ryles, 2004) allowed academics to audit key skills and employability skills at the module level, and across degree pathways. Its use was aimed at quality assurance and to allow staff to reflect on how students' academic experiences might be improved. The mapping template was developed around six key skills ('communication', 'application of number', 'information and communications technology (ICT)', 'improving own learning and performance', 'working with others' and 'problem solving'), with the addition of 'career management'. Another example was a study undertaken at a West Australian university where a proposed model of measuring undergraduate capabilities in employability skills was tested (Jackson, 2014), with the intended outcome of the identification of ways in which graduate skills could be enhanced through reconsiderations of pedagogies and curricula. An online audit was completed by business undergraduates who rated their own level of ability in ten employability skills, which broadly covered working in teams, analytical and communication skills and self-management. 
An online self-audit for students of employability skills formed part of the Liverpool Universal Student Interactive Database (LUSID) (Strivens \& Grant, 2000), which was retired at the end of 2015. This consisted of three sections: (a) Recording, (b) Skills Audit, and (c) Action Planning. Initially, the Skills Audit section asked users approximately a hundred questions in relation to component skills, a number which its authors envisaged would grow over time. More recently, there has been a range of online provision for students to self-audit their employability skills. For example, an online tool provided by the Careers and Employability Service at the University of Kent (University of Kent Careers and Employability Service, 2016), itself part of a wider package of guidance, invites responses to 32 statements about a student's personal skills. A skills profile is then built up based on eight employability skills ('written communication', 'negotiating and persuading', 'verbal communication', 'co-operating', 'investigating and analysing', 'leadership', 'planning and organising' and 'numeracy'). A further example is provided by the 'Personal Skills Audit' provided by Heriot-Watt Careers Service (Heriot-Watt Careers Service, 2016), in which students are invited to respond with an appraisal of their own skill level in a range of employability skills. When completed, suggestions are provided to students on further skills development.

\subsection{The UMA Employability Tool}

The Centre for Inclusive Learning Support at the University of Worcester, together with partners from the Universities of Gloucester and Plymouth led the National Teaching Fellowship (NTFS)-funded project 'Employability and Disability', which completed in 2011 (UseMyAbility, 2011). It aimed to "reduce discrimination and enhance disabled graduates' employability" through providing disabled students with skills that match the various identified employability competences. A web tool developed by Dr. Val Chapman allowed users to use the UseMyAbility (UMA) resource as a 'student', 'employer' or 'lecturer' and then search by employability skill, impairment, subject or by employability skill and impairment. The sixteen identified employability skills are:
1) Adaptability
2) Commercial/sector awareness
3) Information Literacy
4) Interpersonal Skills
5) Literacy-Reading
6) Numeracy
7) Observation/Visual Literacy
8) Oral Communication
9) Practical Skills
10) Problem Solving
11) Self-Management
12) Teamwork
13) Time Management
14) Using ICT
15) Working under pressure
16) Written Communication

Through utilising the various search combinations on the website, users can find information targeted to their exact requirements. The UMA tool developed for use in higher education settings takes the form of an online tool that was hosted by Bristol Online Surveys(Note 1) (BOS) for the two projects described in this paper. This self-audit tool aims to enhance students' understanding of the nature of employability skills and how these might be improved. It also seeks to enable students to establish a benchmark from which to track their development across the range of employability skills.

In the online tool used for the two projects described here, each of the sixteen skills contains six sub-questions (except Teamwork, which has seven); each of these contains a five-point Likert item where ' 1 ' indicates that this area is not yet developed and further significant work is needed, '2' indicates that skill in this area is limited and there are more gaps than strengths, ' 3 ' indicates that this area is acceptable, although there are some gaps or weaknesses which need to be addressed, '4' indicates the area is good, with strengths outweighing areas which need to be developed 
and ' 5 ' indicates the area is excellent and is an outstanding strength. An open text box is also provided for students to provide examples or evidence to support their claim to have developed the specific employability skill. After responding to each sub-question, a composite rating is given for the overall employability skill using a five-point Likert item. A full list of the employability skills and sub-questions can be found in Appendix 1.

\subsection{Rationale}

The Institute of Sport and Exercise Science (ISES) at the University of Worcester states that in terms of employability, it aims to produce the 'complete sports graduate' who "will be equipped with the skills, attributes and knowledge to be able to manage and be effective within their own career and make a significant contribution to society" (University of Worcester, 2015). Key elements of this statement relate to self-awareness and taking control of one's own learning and on-going development and it was with these aspects in mind that the decision to trial the online UMA within ISES was made.

The two groups of students that trialled the use of the UMA tool were (a) a second-year PE module, and (b) students engaged in performance analysis internships. This paper seeks to provide an outline of each of these projects and then analyse the findings from both, with the overall aim of assessing the effectiveness of the UMA tool from both student and staff perspectives. The research question to be addressed was:

How effective was the UseMyAbility (UMA) online tool from the perspectives of the students and staff who engaged with it?

\subsection{Methodology}

Underpinning both of these projects was a social constructivist approach (Vygotsky, 1978), that acknowledges that individuals construct knowledge from their experiences of the world through interaction in social and cultural contexts. Therefore, it was considered important to not only investigate the participant completion of the UMA questionnaire itself, but also utilise qualitative methods to better understand staff and students' attitudes to and experiences of its completion as well as perceptions of its effectiveness.

\section{Methods}

\subsection{Participants}

\subsubsection{The Second-Year PE Module}

All students taking this module were invited to complete the UMA online tool (Beaman-Evans, Chapman, Breeze \& Bowen-Jones, 2015). Its completion was prefaced by an online survey designed to ascertain the baseline level of student knowledge concerning the concept of 'employability'. Owing to the differing type of questions, there was a mixture of provided response types, ranging from 5-point Likert items to open questions. The UMA tool itself was launched following an employability skills session given to students participating in the module. During this session, the students were shown a PowerPoint presentation and engaged in small group/paired activities. They were then informed of the launch of the UMA tool and that they would be able to log on and off as many times as they needed to in the course of its completion. They were then invited to complete the survey over the ensuing two weeks. It was hoped that the completion of the online tool would:

- enhance students' understanding of the nature of employability skills and how they might be improved;

- enable students to establish a benchmark from which to track their development across a range of 16 employability skills;

- help students write better job applications, respond more appropriately to job interview questions, and develop evidence based curricula vitae (CVs), making use of the audit tool and their experience within the project;

- $\quad$ promote the use of the self-audit tool by academic staff across the institute.

Eighty students were eligible to participate, of which 31 attended the presentation. Of these, 20 opened the questionnaire but only 17 of these completed any questions. Thirteen respondents completed over $50 \%$ of the 97 open questions, one student completed all but 14 of these and one completed all but two. The Likert items were completed more frequently than the open questions, with the lowest number of responses to a particular question being 11 and the highest 17. The details of the total responses are summarised in table 1 as a percentage of the highest number of completions, which was 17. As the last two students had completed most of the questionnaire, it was decided to ask these two to participate in a case study in order to explore their perceptions of the process. 


\subsubsection{Internship Students}

Nine students undertaking performance analysis internships with external organisations took part in the project. The internships were undertaken with a range of sporting contexts, for example league football clubs, national teams, cricket and hockey clubs. Students were asked to complete the UMA questionnaire twice, firstly during January and February 2014 and again during May and June 2014. Monthly meetings were held between January and June 2014 between internship students and the two university staff who acted as mentors. It was hoped that the completion of the UMA would allow staff to:

- investigate the efficacy of internships in terms of the development of student employability;

- evaluate the effectiveness of the UseMyAbility online questionnaire for interns.

Nine students completed the UMA questionnaire during January and February, six of whom completed it again during the May to June period.

\subsection{Research Design}

\subsubsection{The Second-Year PE Module}

Data concerning the completion of the UMA questionnaires was collated, following which the two case study students were interviewed individually in order to better understand their experiences. The interview questions focused on how effective the questionnaire tool might have been in changing their awareness of their employability skills, the timing of the questionnaire, what could be improved, any changes to their practice and what use might be made of it to support the development of their curricula vitae, in supporting job applications and job interviews. The interview questions can be found in Appendix 2. Their responses were analysed using the online tool AAT(Note 2), which allowed categories to be created, comparisons made and inferences to be drawn from the raw data.

\subsubsection{Internship Students}

Following the collation of completion data from the nine pre- and six post-internship UMA questionnaires, the two mentors were interviewed together in order to gain a clearer picture concerning the interns' use of the tool, how it was used during the internship itself, whether they had experienced difficulties, the pace of its completion, the role of the monthly meetings with the interns, what went well and what could be improved, and how effective it was in terms of raising students' awareness of their own employability. The interview questions can be found in Appendix 3 . The data gained from this interview was analysed using $\mathrm{AAT}^{1}$.

\section{Results}

\subsection{Completion of the UseMyAbility (UMA) questionnaire}

All students that completed the audit were able to provide a range of responses to the 16 employability skills as well as providing examples to support; one student was able to provide an example for every question asked.

A summary of the UMA questionnaire completion data for all participating students from both groups is presented in table 1 .

It is notable that the internship students have a $100 \%$ completion rate for the grades provided for all questions, as they were required to provide these as part of their course. However, there were clear differences between the pre and post completion rates of the open-text questions for the internship students, i.e. they were much lower in the post iteration. Notably, the PE students' completion rates were the lowest overall. 
Table 1. Summary of UMA Completion Data from Both Groups of Participants

\begin{tabular}{|c|c|c|c|c|}
\hline Employability skill & $\begin{array}{l}\text { Second-year PE } \\
\text { module: } \% \text { grades } \\
\text { provided for Likert } \\
\text { items by all } \\
\text { participants who } \\
\text { responded }(n=17)\end{array}$ & $\begin{array}{l}\text { Second-year PE } \\
\text { module: } \\
\% \text { completed } \\
\text { sub-questions (open } \\
\text { text boxes) by all } \\
\text { participants who } \\
\text { responded }(n=17)\end{array}$ & $\begin{array}{c}\text { Internship } \\
\text { students: } \% \text { grades } \\
\text { provided for Likert } \\
\text { items by all } \\
\text { participants who } \\
\text { responded: } \\
\text { pre }(n=9) \\
\text { /post }(n=6) \\
\end{array}$ & $\begin{array}{l}\text { Internship students: } \\
\% \text { completed } \\
\text { sub-questions (open } \\
\text { text boxes) by all } \\
\text { participants who } \\
\text { responded: } \\
\text { pre }(n=9) \\
\text { /post }(n=6) \\
\end{array}$ \\
\hline Adaptability & $76 \%$ & $34 \%$ & $100 \% / 100 \%$ & $93 \% / 50 \%$ \\
\hline $\begin{array}{l}\text { Commercial/sector } \\
\text { awareness }\end{array}$ & $75 \%$ & $23 \%$ & $100 \% / 100 \%$ & $91 \%$ / 67\% \\
\hline $\begin{array}{l}\text { Information } \\
\text { Literacy }\end{array}$ & $75 \%$ & $23 \%$ & $100 \% / 100 \%$ & $89 \% / 53 \%$ \\
\hline Interpersonal Skills & $75 \%$ & $26 \%$ & $100 \% / 100 \%$ & $89 \% / 42 \%$ \\
\hline Literacy-Reading & $75 \%$ & $16 \%$ & $100 \% / 100 \%$ & $76 \% / 19 \%$ \\
\hline Numeracy & $73 \%$ & $15 \%$ & $100 \% / 100 \%$ & $80 \% / 22 \%$ \\
\hline $\begin{array}{l}\text { Observation/Visual } \\
\text { Literacy }\end{array}$ & $75 \%$ & $15 \%$ & $100 \% / 100 \%$ & $81 \% / 44 \%$ \\
\hline $\begin{array}{l}\text { Oral } \\
\text { Communication }\end{array}$ & $76 \%$ & $14 \%$ & $100 \% / 100 \%$ & $76 \% / 36 \%$ \\
\hline Practical Skills & $76 \%$ & $16 \%$ & $100 \% / 100 \%$ & $81 \% / 47 \%$ \\
\hline Problem Solving & $75 \%$ & $14 \%$ & $100 \% / 100 \%$ & $74 \% / 42 \%$ \\
\hline Self-Management & $99 \%$ & $36 \%$ & $100 \% / 100 \%$ & $89 \% / 47 \%$ \\
\hline $\begin{array}{l}\text { Teamwork (7 } \\
\text { sub-questions) }\end{array}$ & $88 \%$ & $29 \%$ & $100 \% / 100 \%$ & $89 \% / 36 \%$ \\
\hline Time Management & $99 \%$ & $24 \%$ & $100 \% / 100 \%$ & $74 \% / 22 \%$ \\
\hline Using ICT & $81 \%$ & $16 \%$ & $100 \% / 100 \%$ & $74 \% / 39 \%$ \\
\hline $\begin{array}{l}\text { Working under } \\
\text { pressure }\end{array}$ & $76 \%$ & $12 \%$ & $100 \% / 100 \%$ & $70 \% / 31 \%$ \\
\hline $\begin{array}{l}\text { Written } \\
\text { communication }\end{array}$ & $76 \%$ & $14 \%$ & $100 \% / 100 \%$ & $74 \% / 19 \%$ \\
\hline
\end{tabular}

\subsection{Participant Interviews}

In order to analyse the two participant interviews, inductive content analysis was utilised (Thomas, 2006) to code the data into categories from which greater insights could be gained through (a) summarising the data, (b) making explicit links between the research questions and the categorised data, and (c) developing a framework for structuring the students' experiences presented in the data.

\subsubsection{Second-Year PE Module}

Four identified common themes were established into which the responses from the interview questions were categorised:

Enhancement: Increased understanding of employability skills;

Institute of Sport and Exercise Science (ISES) Employability: How ISES could improve students' employability awareness;

Limitations: Weaknesses in the study;

Personal Development: How participants had benefitted from the study and how this knowledge might be used 
in the future.

The four categories are discussed in turn below:

\subsubsection{Enhancement}

Students noted a variety of ways in which they perceived the study had aided their understanding of employability skills and that they had found the presentation session and completion of the audit tool useful in building their awareness and knowledge. A selection of responses to selected questions is presented below:

In answer to the question "Which aspect of your engagement with the project would you say had had the most impact on you?" a participant noted:

"The audit [...] I could see what I had done to enhance my employability."

When asked "How effective did you find the audit?" one response was:

"Very helpful how you could give your experiences [...] All the different skills and all the different aspects of those skills so you could really think about it and think about how you could improve ..."

\subsubsection{ISES Employability}

In response to the question "How do you think ISES could further improve your employability skills?", suggestions included expanding its scope and regularity:

"Making the questionnaire available to people who want to enhance their employability skills [...] I think that would really help them."

"I think [work experience] might enhance employability if you had the chance to do it every year."

\subsubsection{Limitations}

Students were able to identify a number of limitations with the study and proposed some suggestions for changing it in order to make it more accessible for future users. When asked "Which aspects of the project's activities could be improved?", one participant suggested a reconsideration of its timing:

"It was at a bit of an awkward time... If it was done like at the start of semester one maybe [...] that would have been a better time ... I was more focused on getting my assignments done ..."

However, one student liked the time of completion at the end of the second year as it allowed them to consider their employment prospects at the end of third year:

"For me it possibly was a little off time ... but having it at the end of the 2nd year really opened your eyes and think about having to be employed at the end of your 3rd year."

The length of the UMA questionnaire was an issue, particularly for one student, who didn't have time to complete all the text-based sub-questions. Allied to this was the lack of a progress bar. They noted:

"The questionnaire was very very long- the second one...The hardest part was the fact like it didn't really have, like on most questionnaires you can see how far along you're getting ..."

A particular request was:

"The thing I would change if I wanted to change anything would be to allow me to leave something blank. So I could come back to later..."

\subsubsection{Personal Development}

When asked "What use will you make of your completed audit to support the development of your CV, to support job applications and job interviews?" responses included:

"I will be taking it along with me, I'll be keeping it up to date ... show evidence and taking it along to interviews ... maybe you could post it online with a CV ..."

"I'll definitely add those skills that are in there and put them into my statement and refer to times when I have used them ... in term of interviews and things, I think it will really help."

\subsubsection{Internship Students}

Eight categories were identified following the inductive content analysis of the mentor interview.

Difficulties: Problems or difficulties encountered completing the survey;

General effectiveness of the UMA tool: General comments concerning the effectiveness of the UMA 
questionnaire;

How the UMA questionnaire was completed: How and when the UMA questionnaire was completed by the students;

Improvements: Aspects of the use of the UMA questionnaire that could be improved;

Monthly meetings: issues surrounding the monthly meetings between tutors and interns;

Relevance: The relevance of the UMA questionnaire to the performance analysis context;

Usefulness of tool: How useful the tool was to the interns;

What worked well: What worked well regarding the use of the tool in the performance analysis context.

Each of these is discussed in turn below:

\subsubsection{Difficulties}

The two mentors noted that there had been occasional questionnaire administrative issues in saving the interns' responses owing to not enabling the option to save as the respondent completes parts of the tool. A further issue related to the interns not wanting to complete the qualitative parts of the tool as readily as the Likert items. Although interns had been willing to participate, they had seemed to want to spend more time out in the field working with their client rather than on reflecting on aspects of their employability.

\subsubsection{General Effectiveness of the UMA tool}

Owing to the way the tool was used in this context, pre and post, the two mentors both commented that it was useful for interns to acknowledge what they had done and how they had progressed between iterations of the questionnaire. It was considered to be a good reference point for interns so that they could readily see the benefits of their placement. However, it was also felt that there were still questions concerning how it could be best implemented in the performance analysis context, especially as interns had reported that it took about an hour-and-a-half to complete.

\subsubsection{How the UMA Questionnaire was Completed}

Both mentors noted that interns had generally completed the questionnaire after a lecture whilst at the University. It was available to be used on a mobile device but only one or two had used an iPad or a tablet. Both mentors had been available to provide support as needed. As previously noted, the majority of the interns completed the quantitative Likert items and many omitted the qualitative open text boxes. The pacing of the tool's completion was considered important as it was thought to be best completed before and after the placement rather than during it, when the intern would be focused on gaining experience on the internship.

\subsubsection{Improvements}

The length of the questionnaire was thought to be a major impediment to its completion by the interns. Owing to the quantitative and qualitative elements for each of the 114 questions, it was considered long; a possible solution to this that was put forward was whether there might be one qualitative section per skill, rather than for each sub-skill, to summarise that particular area. Although it is a generic tool, the two mentors considered it to cover the areas they wanted their interns to reflect upon and what they need to develop in order to be employable within their field. They didn't feel there were any omissions, and although it could be more specific towards particular roles (such as scouting, opposition analysis, post-match analysis and real-time analysis), they all rely upon a similar basic skill set. To be more usable in the field, the mentors felt that it would be necessary to have the tool available as an app for a mobile device that could sync when a suitable signal was present but would allow for off-line working otherwise.

\subsubsection{Monthly Meetings}

It was felt by both mentors that the monthly meetings had helped the completion rate of the tool. One particular aspect was that they considered the meetings became less formal as the placement progresses and ideally they would like to maintain their earlier formality throughout.

\subsubsection{Relevance}

It was felt that the tool was relevant to the various contexts that interns found themselves placed in. All the performance analysis placements are very different and it was noted that various attributes related better to different contexts. Although some attributes could have been personalised to particular contexts, it was thought that this was not desirable; notably, it was thought that there were no questions that were not useful. 


\subsubsection{Usefulness of Tool}

The two mentors agreed that for them, a central question concerning the use of the tool was "are the students in a better position to understand their employability strengths and weaknesses and how these can be addressed?" Although they were unable to say that the tool had unequivocally made the interns more employable, on the other hand, it was felt that it could only help them to become more reflective on their own progression. It was thought that the tool had given the interns an appreciation that becoming more employable was not just about working as an analyst for a period of time but was really about the whole package and the skills that are developed while placements are being undertaken.

\subsubsection{What Worked Well}

The main strength of the tool was considered to be the reflection and understanding that interns would gain, particularly regarding what they need to get better at and which areas they need to improve throughout their placement. The first conversation that the mentors had had with the interns was seen to be of particular importance as it was at that meeting that they felt the interns' engagement in the training programme really started and they could see which skills they needed to work on. In particular, the tool had been found to be a good reference point for discussion.

\section{Discussion}

\subsection{Enhancement}

The results of the interviews from both studies confirmed that participating students were able to identify a variety of ways in which the completion of the questionnaire had informed their notions of their own employability skills. In particular, for the internship students, it had provided evidence of progression, raised students' awareness, gave a reference point and helped them to better understand their strengths and weaknesses. The PE students suggested that there were ways in which they could take the knowledge they had gained from completing the questionnaire into their CVs, applications and interviews. They also suggested that the questionnaire could be employed more widely across the University and that it would be good if there was the opportunity to undertake work experience during every year of study. The internship mentors also noted that the questionnaire had enhanced students' reflective skills and had formed a useful reference point for discussion.

\subsection{Relevance to Context}

The internships undertaken by the students were all very different; however, it was interesting to note that although the two mentors felt that the questionnaire was relevant to all of these, and that there were various attributes that were better related to specific contexts, they did not feel that the it should be personalised to these contexts but rather left in its original form. The two PE case study students also confirmed that the questionnaire had been relevant to their contexts.

\subsection{Does Completing the Questionnaire Make Students More Employable?}

The two internship mentors noted that they couldn't say definitely that the questionnaire itself had made the students more employable. However, they maintained that its usefulness lay in indicating progression in its pre and post iterations, it provided a good reference point for discussion at the monthly meetings, it encouraged the students to be reflective and to appreciate what it took to be employable. In particular, the two mentors felt that the timing of the pre and post iterations was good, because it gave student the time in-between to focus on their placement.

\subsection{Practical Outcomes}

The immediate practical applications of the survey mentioned by the two PE students regarding applying the knowledge gained to their curricula vitae, job applications and interviews was notable, as well as their comments relating to keeping the Excel file that had been downloaded from the questionnaire up-to-date and possible uses of the information online and in connection with personal statements.

\subsection{Technical}

A few comments related to technical issues connected with the questionnaire itself, ensuring that it was possible for students to save and resume their completion of it, the addition of a completed amount indicator, both of which are possible to enable within the survey software. Another aspect raised was that of students completing the questionnaire while on placements and perhaps not within reach of a reliable Wi-Fi signal. A solution to this issue that was suggested by one of the internship mentors was that it would be an improvement to have the questionnaire 
available on a mobile tablet device that would allow local saving and syncing when a signal was available. This would allow students to complete it at a convenient time and place to them during the placement without needing to check that a signal was available.

\subsection{Limitations}

The two modes of completion of the UMA questionnaire raised distinct issues. In the case of the second year PE module, only two of the participants completed the entire questionnaire in the manner anticipated within the somewhat limited two-week time period, responding to nearly all the questions. Although three potential respondents chose not to complete any of the questionnaire, it was notable that thirteen respondents completed over $50 \%$ of the 97 open questions. The Likert items were answered consistently more often than the open text questions, between $73-76 \%$ for 12 of the questions, with a much higher response rate for 'Self-Management', 'Teamwork', 'Time Management' and' Using ICT' of between $81-99 \%$. It is not known why there is this discrepancy between the two sets of questions but it is hypothesised that the questions with the higher response rate were of greater relevance to the participants.

It is possible that survey fatigue (Adams \& Umbach, 2012, p. 579) may have been a factor in the completion of the open-text boxes. In the PE completions, there are two high points at 'Adaptability' and 'Self-Management'; following each of these, there is a decline in completions see table 1). This is reflected in a less marked way in the completions of the two iterations of the questionnaire by the internship students, but it is notable that the second iteration has a much lower response rate.

Following the two case study interviews, it was clear that although the timing of the questionnaire wasn't perfect, its completion it at the end of the second year was a good time in general. However, the two students found it overly long to complete within the time frame. The requested time bar feature that was mentioned is already offered by the software and can be readily implemented.

In the case of the internship students, the pre- and post-internship completion of the questionnaire resulted in a more consistent and higher completion rate, although there was a notably lower completion rate of the open questions in the post-internship iteration (see table 1). As with the second year PE module, the two mentors felt that the questionnaire was too long. It is possible that the length of the questionnaire length might have had an impact on the number of students who were able to complete it (Galesic \& Bosnjak, 2009), although it should be noted that neither of the scenarios described in this paper were able to allow the students to complete it exactly in the way originally anticipated, as an ongoing developmental tool over a longer period of time. However, its use in a pre and post context did allow the two mentors to identify changes brought about in the students' perceptions of their employability skills before and after their internship and it was noted that it had provided a good basis for discussion.

\section{Conclusion}

Overall, the use of the UMA within the second-year PE module and internship contexts was considered to be successful. However, as it was the first time that the tool had been used by the participating lecturers and students, there were some recommendations that were made:

- Embedding it into a programme of study as a mandatory element that was re-visited at regular intervals, as in the internship project, resulted in a higher completion rate overall;

- The questionnaire was considered rather long, and a suggestion was made to reduce it, perhaps by providing an open text box for each overall employability skills rather than each sub-skill. This would result in 16 open text boxes overall;

- Apps developed for tablet devices that would allow offline access and would sync as a signal is available;

- Particularly following on from the comments of the second-year PE module participants, the timing should be considered carefully and the amount of time needed for students to complete it be re-evaluated;

- Although it was employed in these studies within a range of contexts, its generic nature was considered to be a strength and it was not felt necessary to personalise it for specific situations.

All the comments made about its usefulness in terms of developing skills, building awareness of employability, benchmarking and aiding reflection were positive and it is suggested that overall the questionnaire is of great benefit in an undergraduate sports context. It is suggested that it should now be trialled in a greater variety of academic contexts and its usefulness measured and compared leading to the construction of a more comprehensive picture of its ability to support student employability. 


\section{References}

Adams, M., \& Umbach, P. (2012). Nonresponse and Online Student Evaluations of Teaching: Understanding the Influence of Salience, Fatigue, and Academic Environments. Research in Higher Education, 53(5), 576-591. http://dx.doi.org/10.1007/s11162-011-9240-5

Beaman-Evans, C., Chapman, V., Breeze, N., \& Bowen-Jones, W. (2015). 'Usemyability' (UMA). An investigation into whether an online employability skills audit can enhance students understanding of the term employability. Worcester Journal of Learning and Teaching, 10. Retrieved March 11, 2016, from http://www.worc.ac.uk/edu/documents/Usemyability.pdf

Callanan, G., \& Benzing, C. (2004). Assessing the role of internships in the career-oriented employment of graduating college students. Education + Training, $46(2), \quad 82-89$. http://dx.doi.org/10.1108/00400910410525261

Confederation of British Industry (CBI) (2009). Future fit: Preparing graduates for the world of work. Retrieved March 10, 2016, from http://www.cbi.org.uk/media/1121435/cbi_uuk_future_fit.pdf

Dacre Pool, L., \& Sewell, P. (2007). The key to employability: developing a practical model of graduate employability. Education + Training, 49(4), 277-289. http://dx.doi.org/10.1108/00400910710754435

Dacre Pool, L., Qualter, L., \& Sewell, P. (2014). Exploring the factor structure of the CareerEDGE employability development profile. Education + Training, 56(4), 303-313. http://dx.doi.org/10.1108/ET-01-2013-0009

Dearing, R. (1997). Higher Education in the learning society. Retrieved March 10, 2016, from http://www.educationengland.org.uk/documents/dearing1997/dearing1997.html\#ana

Galesic, M., \& Bosnjak, M. (2009). Effects of Questionnaire Length on Participation and Indicators of Response Quality in a Web Survey. Public Opinion Quarterly, 73(2), 349-360. http://dx.doi.org/10.1093/poq/nfp031

Gillespie J. (2001). Higher education and key skills. Retrieved March 11, 2016, from http://www.qualityresearchinternational.com/esecttools/esectpubs/gillespiekeyskills.pdf

Harvey, L. (2001). Defining and Measuring Employability. Quality in Higher Education, 7(2), 97-109. http://dx.doi.org/10.1080/13538320120059990

Harvey, L. (2000). New realities: The relationship between higher education and employment. Tertiary Education and Management, 6(1), 3-17. http://dx.doi.org/10.1080/13583883.2000.9967007

Helyer, R., \& Lee, D. (2014) The Role of Work Experience in the Future Employability of Higher Education Graduates. Higher Education Quarterly, 68(3), 348-372. http://dx.doi.org/ 10.1111/hequ.12055

Heriot-Watt Careers Service (2016). Are You Employable? -An International Students Guide to Employability Skills. Retrieved March 11, 2016, from http://www1.hw.ac.uk/careers/skills/start.php

Higher Education Academy (2015). Higher Education Achievement Report. Retrieved March 11, 2016, from http://www.hear.ac.uk/

Higher Education Quality Council (HEQC) (1997). Graduate Standards Programme: Final Report (Two volumes). London: HEQC.

Jackson, D. (2014). Testing a model of undergraduate competence in employability skills and its implications for stakeholders. Journal of Education and Work, 220-242. http://dx.doi.org/10.1080/13639080.2012.718750

Kubler, B., \& Forbes, P. (2005). Student Employability Profiles: A Guide for Employers. London: The Council for Industry and Higher Education.

Stratta, T. (2004). The Needs and Concerns of Students during the Sport Management Internship Experience. Journal of Physical Education, Recreation \& Dance, 75(2), 25-29. http://dx.doi.org/10.1080/07303084.2004.10608555

Strivens, J., \& Grant, S. (2000). Integrated Web-based support for learning employability skills. Educational Technology \& Society 3(1) Retrieved March 11, 2016, from http://www.ifets.info/journals/3_1/strivens.html

Tariq, V., Scott, E., Cochrane, A., Lee, M., \& Ryles, L. (2004). Auditing and mapping key skills within university curricula. Quality Assurance in Education, 12(2), 70-81. http://dx.doi.org/ 10.1108/09684880410536440

Thomas, D. (2006). A General Inductive Approach for Analyzing Qualitative Evaluation Data. American Journal of Evaluation, 27(2), 237-246. http://dx.doi.org/10.1177/1098214005283748 
University of Kent Careers and Employability Service (2016). Employability Skills Exercise. Retrived March 11, 2016, from http://www.kent.ac.uk/careers/sk/skillstest.html

University of Worcester (2015). Employability. Retrieved March 10, 2016, from http://www.worcester.ac.uk/discover/sport-employability.html

Use My Ability (2011). Employability and disability project. Retrieved March 10, 2016, from http://usemyability.com

Vygotsky, L. (1978). Mind in Society. London: Harvard University Press.

Wilson, T. (2012). A Review of Business-University Collaboration, Department of Business, Innovation and Skills. Retrieved March 10, 2016, from https:/www.gov.uk/government/uploads/system/uploads/attachment_data/file/32383/12-610-wilson-review-bus iness-university-collaboration.pdf

Wright, J., Brinkley, I., \& Clayton, N. (2010). Employability and Skills in the UK: Redefining the debate. Retrieved March 10, 2016, from

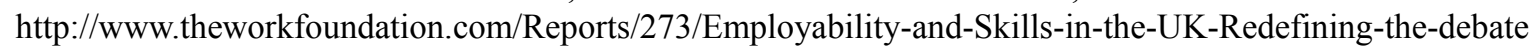

Yorke, M. (2006). Employability in higher education: what it is - what it is not. Retrieved March 11, 2016, from https://www.heacademy.ac.uk/sites/default/files/id116_employability_in_higher_education_336.pdf

\section{Notes}

Note 1. See: https://www.onlinesurveys.ac.uk/

Note 2. See: http://www.nbreeze.uk/aat-manual.pdf

\section{Appendices}

\section{Appendix 1: UMA - The 16 Employability Skills and Sub-Questions}

\section{Adaptability}

Can you solve problems creatively?

Can you deal with uncertain and/or unpredictable work situations?

Are you good at learning new technologies, new tasks or procedures?

Do you have interpersonal adaptability - are you able to work effectively with a wide range of people?

Are you able to adapt to different cultures?

Are you able to adapt quickly to a range of physical environments?

\section{Commercial/sector awareness}

Do you show an active interest in the particular sector that is relevant to your future employment?

Do you have good customer/client care skills?

Are you economically and politically aware?

Are you creative and innovative?

Do you have strategic awareness?

Are you knowledgeable about your work sector and issues that are likely to impact upon it?

\section{Information Literacy}

Can you identify when there is a need to gather information?

Can you gather and filter information from a range of different sources?

Do you store and organise information in structured, easily accessible formats? 
Are you good at critically evaluating data to establish research legitimacy and credible theoretical foundations?

Can you apply information in a practical context?

Can you present information and your analysis orally or in writing?

\section{Interpersonal Skills}

Are you good at listening to others?

Are you able to manage conflict effectively without getting annoyed or upset?

Do you behave appropriately in the different situations in which you find yourself?

Can you adapt readily to the context in which you find yourself?

Are you able to establish rapport with others quickly and easily?

Can you collaborate effectively with others?

\section{Literacy-Reading}

Are you an effective reader at the level demanded by your programme of study?

Can you construct an opinion of the text, based on your perceptions and prior knowledge, to determine how the text is relevant to your needs?

Are you able to read critically in order to identify bias, inconsistencies and contradictions in a text?

Can you read quickly enough to satisfy the demands of your course?

Are you effective at proof reading your own writing?

Do you understand a range of symbols/languages relevant to your programme of study (e.g. instructions shown through pictograms)?

\section{Numeracy}

Do you have a good understanding of mathematics?

Are you able to use the language of maths effectively to express and conceptualise mathematical ideas?

Do you have a good understanding of mathematical concepts?

Are you effective at gathering and storing data in an appropriate format, e.g. spreadsheets or databases?

Can you interpret and communicate mathematical data to others?

Can you use maths in a practical context?

\section{Observation/Visual Literacy}

Can you relate your knowledge and theory to a practical or working environment?

Are you good at paying attention to detail in order to identify errors and/or inconsistencies in your work?

Can you remain highly focused on the task in hand, possibly for long periods of time?

Are you good at visual analysis - observing and assessing an event to get a comprehensive understanding of it and its various elements?

Do you have a good visual memory?

Are you good at observing and interpreting body language?

\section{Oral Communication}

Auditory processing: are you effective at processing sequences, sounds and words quickly to follow what is being 
said even on unfamiliar topics?

Are you able to understand (decode) the sounds/speech that you hear quickly and easily even when someone uses complex or abstract language?

Are you good at always finding the right words to express yourself orally?

Do you always use, where necessary, appropriate grammatical forms to put your ideas into words?

Are you good at achieving rapport with your audience, whoever they are?

Can you usually find the right words and use them in the right way for the situation in which you find yourself?

\section{Practical Skills}

How effective are you at applying the knowledge and theory you have gained from your educational experiences?

Do you have good common sense? Please give some examples of when you have used common sense.

Are you able to complete practical activities safely having regard for yourself and others?

Do you always employ best practice where it is feasible and applicable to the practical situation you are working on?

Are you always conscious of what is expected of you and how your performance will be judged?

Are you a proactive worker?

\section{Problem Solving}

Do you usually approach problem solving in a systematic way?

Do you usually know where to look for the relevant information you need?

Are you able to establish different points of view as well as the stakeholders' interest in relation to the problem and potential solutions?

Are you able to think critically as well as creatively to make good decisions?

Are you good at recommending a solution - can you usually justify its merit and the logic behind the decision process?

Do you always follow through - can you implement a solution and monitor the results?

\section{Self-Management}

Do you have initiative? Are you able to identify new work opportunities, challenges and responsibilities?

Are you good at planning: setting achievable and realistic goals, then implementing a systematic and organised strategy to achieve these?

Are you able to motivate yourself - do you pursue tasks with energy, drive and enthusiasm?

Do you work with determination - can you work towards a goal despite difficulties, setbacks and distractions?

Do you always try to achieve a high level of performance - do you take personal responsibility to exceed standards and expectations?

Do you evaluate your own performance - do you reflect on your own performance and take account of feedback in order to understand your strengths and weaknesses?

\section{Teamwork}

Are you a supportive team member who is able to create a positive ethos?

Do you always make certain you have a clear idea of your role within the group so that you can complete the tasks expected of you?

Are you able to work effectively with a diverse range of people with different backgrounds, experiences and attitudes - do you acknowledge and respect different opinions that emerge from the group? 
Are you able to work effectively with a diverse range of people with different backgrounds, experiences and attitudes - do you always acknowledge and respect different opinions that emerge from the group?

Are you good at managing conflict - do you take action to resolve conflicts and avoid cliques in the group?

Can you behave in a selfless way - are you willing to contribute to the team's objectives even if they contradict your own personal interests and goals?

Can you take on a leadership role - can you allocate tasks within the group dependent on the members' skills, interests and expertise?

13. Time Management

Are you good at setting goals - deciding what you want to achieve within a certain time frame?

Are you good at planning - establishing what tasks and actions you need to undertake to achieve your goals and structuring your time to determine when you will achieve the different tasks and objectives?

Are you effective in prioritising tasks in a logical and manageable way and in accordance with the demands of the working environment?

Are you always punctual and able to meet deadlines?

Do you analyse your working practices to establish areas or routine tasks where you are not getting the most out of your time?

Are you good at protecting your time?

\section{Using ICT}

Are you confident using core computer programmes to produce digital information, e.g. Microsoft Word and Microsoft PowerPoint?

Are you proficient in using spread-sheet and database software which enables the storage, organisation and analysis of larger sets of data (e.g. Microsoft Excel and Access)?

Are you confident in using e-mail, web browsers and social media to access internet-based digital information and integrate with other ICT users?

Are you able to create digital information for a specific task using specialised software (e.g. using Photoshop for graphic design or MS Publisher)?

Are you competent at engaging in technology-enhanced learning systems and processes such as: live broadcasts; mobile video/audio telecommunications; Virtual Learning Environment (VLEs) or 3D graphics?

Do you operate at an advanced level of ICT literacy - do you have a clear understanding of computer operating systems and an ability to write new software?

\section{Working under pressure}

Are you able to stay in control of your emotions and remain calm in difficult situations?

Do you normally take time to assess the situation and rationally identify the key factors and potential solutions available?

Are you effective at planning - do you usually take time to develop a logical and realistic plan that is broken down into manageable tasks?

Do you usually recognise when you are feeling stressed and take effective actions to ease pressure on yourself?

Can you recognise others' points of views but be assertive, when necessary, to get the job done?

Do you avoid leaving things until last minute in order to avoid pressurising yourself?

\section{Written Communication}

Are you competent at formulating and articulating ideas - do you present written information in a logical sequence to make it reader-friendly, making sure that the message is relevant to its subject area and of interest to the reader? 
Do you ensure that your documents have correct spellings - do you making effective use of spellcheckers and/or use others to proof read your work that will be published more widely?

Do you always present your work with correct grammar and punctuation?

Are you able to write a range of documents to a high standard including, for example, correspondence (emails and letters), reports, organisational marketing material and taking notes in meetings; recording thoughts, arguments, instructions, summaries and technical information?

Do you always utilise an effective document style that makes good use of paragraphs, bullet points and headers?

Do you support written documents, where appropriate, with graphs and images?

\section{Appendix 2: Second-Year PE Module Interview Questions}

1. Has your awareness and understanding of employability skills changed as a result of being involved in the Developing Students' Employability Skills project?

2. Which aspect of your engagement with the project would you say had had the most impact on you?

3. How effective did you find the 2nd questionnaire/audit?

4. How did you find the timing of the 2nd questionnaire/audit?

5. How effective and enjoyable did you find the introductory session with Val Chapman?

6. Which aspects of the project's activities could be improved?

7. How do you think ISES could further improve your employability skills?

8. As a result of engaging with the project, what changes to your own practice will you make?

9. What use will you make of your completed audit to support the development of your CV, to support job applications and job interviews?

\section{Appendix 3: Internship Mentors - Interview Questions}

1. In general, how effective did you feel the UseMyAbility online audit tool was?

2. How did the students you mentored use the online audit tool?

3. Did students report they had experienced any particular difficulties using the tool? If so, what were these?

4. Do you think some of the questions asked in the online audit tool were more useful than others? If so, which were these?

5. Were you able to pace students' use of the tool successfully, so that they completed a part of it on a regular basis?

6. How did you feel the monthly meetings with students contributed to the effective use of the audit tool?

7. What do you think worked particularly well regarding the use of the audit tool?

8. Do you think the use of the audit tool in this context could be improved? If so, how?

9. Do you think the audit tool itself could be improved?

10. Would you say that students, as a result of having used the tool, were now in a position to better understand their employability strengths and weaknesses and how they can address these?

11. Have you any other comments you would like to make? 